\title{
"La profesionalidad no tiene sexo": estrategias empresariales y prácticas de profesionalización en el sector de comercial de seguros
}

CARMEN MoZo GonZÁlez*

Avanzada ya la década de los 90 , las desigualdades sociales en función del sexo se consideran vestigios de una situación globalmente superada. El ámbito de la producción mercantil no es ajeno a estos planteamientos. Si una clara división sexual ha caracterizado a la mayor parte de los sectores productivos, en la actualidad y de forma creciente, estos tienden a demandar su fuerza de trabajo en términos asexuados.

Con el objetivo de conocer qué realidades sociales subyacen a este tipo de situaciones, hemos analizado un sector de actividad "moderno", esto es, un sector que no demanda hombres o mujeres, ni exclusiva ni diferencialmente, ya que la ideología sobre la igualdad de oportunidades anula estas diferencias, sino individuos, capacitados y competentes: el sector comercial de seguros ${ }^{1}$.

La profesión de agente de seguros se plantea como una profesión liberal, competitiva y con grandes perspectivas de futuro. Las compañías aseguradoras se dirigen al mercado de trabajo demandando personas con "ambición, iniciativa y competitividad", requisitos estos que en la actualidad se consideran imprescindibles para "triunfar" en el ámbito labo$\mathrm{ral}^{2}$. El sector seguros se define, pues, como un sector "moderno", y este discurso se elabora en constante y recurrente contraste con una situación "tradicional".

* Profesora Asociada del Departamento de Antropología Social de la Universidad de Sevilla.

${ }^{1}$ Este articulo forma parte de una investigación más amplia, culminada como tesis doctoral y leída en Junio de 1.995 en el Departamento de Antropología Social de la Universidad de Sevilla bajo la calificación de apto cum laudem por unanimidad, y dirigida por el Dr. Isidoro Moreno Navarro en el marco del Grupo de Investigación para el Estudio de las Identidades Socioculturales, G.E.I.S.A.

${ }^{2}$ Las políticas económicas neoliberales insisten en la importancia de las actitudes de los trabajadores y las trabajadoras como requisitos fundamentales para incorporarse y permanecer en el mercado de trabajo, trasfiriéndoles así la responsabilidad de su situación laboral. 
La "modernidad", en la línea de lo políticamente correcto ${ }^{3}$ y en contraste con la situación "tradicional", implica un planteamiento asexuado del espacio de la producción. El objetivo del presente artículo es poner de manifiesto que la fuerza de trabajo no es asexuada y que este factor no es ajeno ni al diseño de las estrategias empresariales ni al ejercicio profesional de los y las sujetos sociales implicados en la venta de seguros; esto es, ejemplificar cómo las relaciones sociales de sexo, entendidas como una construcción social dinámica, viva y en continua reelaboración, impregnan y atraviesan las relaciones sociales de producción imbricándose en las culturas del trabajo de los trabajadores y las trabajadoras del sector comercial de seguros en Andalucía ${ }^{4}$.

\section{La profesionalidad no tiene precio}

El discurso sobre la situación "tradicional" en la venta de seguros se podría resumir en los siguientes rasgos: las empresas de seguros comercializaban sus productos a través de la figura del inspector, un hombre que se dedicaba a viajar por la provincia, que pernoctaba cuando las distancias lo hacían necesario, y que vendía los seguros a través de la figura del avisador, un agente nombrado a su cargo. Se buscaba un "centro de influencia", esto es, una persona que en cada localidad facilitase al inspector una red de relaciones que le pusiera en contacto con sus potenciales clientes. En sus visitas, los horarios y los lugares en los cuales se formalizaban los contratos de seguros eran aquellos frecuentados por estos tras la jornada laboral: bares, tabernas, casinos... "Como pasa en toda Andalucía, los seguros se hacen siempre en los bares, no es como en mi tierra, que se hacen los seguros tranquilamente en casa. Aqui no, aqui en casa no se hace nada". Estas palabras de un inspector jubilado, de Palencia, están poniendo de manifiesto formas de interacción social de los hombres andaluces ${ }^{5}$.

Este mundo de inspectores y agentes de seguros avisadores, lo que hoy se conoce como red tradicional, se configuraba como un mundo de hombres. Los agentes avisadores

${ }^{3}$ El escritor J. Finn Ganner, con excelente humor, ha reescrito toda una serie de cuentos clásicos desde "lo políticamente correcto", esto es, ausentes de cualquier muestra de actitudes "sexistas, racistas, culturalistas, nacionalistas, regionalistas, intelectualistas, socioeconomicistas, etnocentristas, falocentristas, heteropatriarcales o discriminatorias por cuestiones de edad, aspecto, capacidad física, tamaño, especie u otras no mencionadas" (Finn Ganner, J. (1.994) p.11).

${ }^{4}$ El ámbito espacial concreto en el que se ha llevado a cabo la investigación es la provincia de Sevilla.

${ }^{5}$ La mayor parte de los estudios realizados sobre la sociabilidad andaluza, aunque no lo expliciten ya que, en una visión androcéntrica de la realidad social, toman la parte (el hombre andaluz) por el todo (la población andaluza), analizan sólo la sociabilidad masculina, estando por tanto el estudio de la sociabilidad de las mujeres mucho menos desarrollado. 
eran varones con una posición social influyente en su localidad: alcaldes, funcionarios del Ayuntamiento, jueces de paz..., o bien personas que por su actividad estaban en contacto con amplios segmentos de población: carteros, policías, transportistas... Pocas, por no decir ninguna mujer de la época ocupaba esa posición social o desarrollaba actividades que le permitiesen establecer contactos. Mas allá de su círculo familiar y de su vecindad, sus relaciones sociales se establecían a través de sus maridos u otros hombres de su grupo doméstico. Las mujeres, en los pueblos andaluces, ya fuesen amas de casa, ya fuesen además trabajadoras asalariadas (en la agricultura o en el servicio doméstico fundamentalmente), no ocupaban posiciones con prestigio social.

Tampoco había mujeres inspectoras. Aún contando con la posibilidad de que alguna mujer hubiese podido acceder a esta categoría laboral, el inspector desarrollaba su actividad a través de una relación personal con los agentes y los clientes. Por las razones ya expuestas, las mujeres quedaban excluidas. ¿Hubiese sido posible una mujer en la posguerra viajando en bicicleta, en moto o en tren por los pueblos andaluces, y tomando café o aguardiente en el casino o en la taberna para formalizar una póliza de seguros?.

Por el contrario, la situación actual, "moderna", desde un planteamiento dicotómico de la realidad característico del pensamiento occidental, se define en oposición a los hechos descritos. Si "lo tradicional" se equipara a lo "no profesional" (escasa cualificación técnica), y esto se identifica con "lo rural", "los bares", "el compadreo" y, en consecuencia, "los hombres", "lo moderno" se va a identificar con "lo profesional" (el énfasis en la cualificación), con nuevos espacios, con la asepsia en las relaciones (un servicio muy personalizado pero a la vez anónimo: "el cliente") y, por tanto, con la asexuación. Se plantea que actualmente la profesionalidad es independiente del sexo de quienes ejercen dicho trabajo: "Yo creo que hoy no prima ya el que seas hombre o mujer sino que priman los rendimientos y los resultados". La utilización de los adverbios temporales "hoy" y "ya" están haciendo referencia, por defecto, a una situación pretérita en la que el sexo sí tenía primacía. Así que, en palabras de un director comercial, como "ninguna compañía de seguros puede poner ningún rechazo ni ningún reparo, porque lo que quiere es negocio, y el que venda, vende", la presencia de una gran mayoría de hombres sólo es explicada como una reminiscencia del pasado, como "una cosa que viene ya de herencia", en línea con los planteamientos de la igualdad de oportunidades entre hombres y mujeres ${ }^{6}$.

Hasta los años 60 , existía una falta de coordinación en la política legislativa respecto al sector. El mercado estaba muy atomizado y se caracterizaba por poseer un número muy

${ }^{6}$ Esta idea de que la producción no tiene sexo se reproduce también a nivel teórico, y está presente tanto en los planteamientos neoliberales como en los neomarxistas. 
elevado de entidades aseguradoras, muchas de ellas pequeñas, familiares y de ámbito reducido, y con unos bajos niveles đe capitalización. $\mathrm{El} \mathrm{ramo}^{7}$ mayoritario en esta década, el de Automóviles, experimentaba altos déficits: prácticamente todas las entidades de seguros españolas multirramos declaraban pérdidas debido a los altos costes de gestión y a las altas tasas de siniestralidad.

A partir de los años 60 , en un proceso que se intensifica en la década de los 80 , esta situación sufre un profundo proceso de transformación que se podría resumir en: un proceso de concentración del mercado mediante adquisiciones, fusiones y ventas, un proceso de rentabilización del capital a través de la reducción de los altos índices de siniestralidad y de los elevados niveles de gastos, tanto internos como externos ${ }^{8}$, y un proceso de intensificación del esfuerzo de ventas como medio de aumentar las cuotas de mercado.

Estos procesos se acentúan fuertemente en la década de los 80: la integración de España en la CEE en 1.986 y la perspectiva del mercado único europeo provocan una incremento del capital extranjero en el sector, apareciendo un gran número de entidades que ofrecen sus productos a precios competitivos con el fin de ganar cuotas de mercado. La consolidación de un contexto cada vez más competitivo intensifica la ya señalada tendencia hacia concentración del mercado.

Durante esta década culminan los esfuerzos legislativos tendentes a suplir una legislación fragmentaria e insuficiente y a liberalizar el sector ${ }^{9}$.

Aunque Automóviles continúa siendo de hecho el ramo con más peso, aquellos de los que se espera un mayor crecimiento son los ramos de Vida y Salud ${ }^{10}$.

${ }^{7}$ Ramo: Conjunto de modalidades de seguros relativas a riesgos de características semejantes: ramo de Vida, ramo de Automóviles, ramo de Incendios...

${ }^{8}$ Es de destacar el papel que ha jugado la informatización en el proceso de control de las redes agenciales puesto en marcha con el objetivo de reducir gastos extemos.

Los Seguros son considerados como uno de los sectores en los que la introducción de la informática se ha realizado de una forma más intensiva. En este sentido, las investigaciones realizadas se han planteado básicamente el estudio de las repercusiones de la informatización en la naturaleza y control de los procesos de trabajo administrativos (ver por ejemplo Verdier (1.980)), pero es de destacar así mismo el incremento de los niveles de informatización como una vía fundamental de aumentar el control de la gestión y realizar un seguimiento más exhaustivo de la producción y la siniestralidad de los y las agentes de las compañías aseguradoras.

${ }^{9}$ Ley de contrato del seguro, Ley 50/1.980 de 8 de Octubre y Ley de Ordenación del Seguro Privado, Ley 33/ 1.984 de 2 de Agosto. En 1.992 se publica la Ley de Mediación del Seguro, Ley 9/1.992 de 30 de Abril que liberaliza los canales de comercialización de Seguros privados.

${ }^{10}$ Es de señalar cómo históricamente la importancia de unos u otros ramos del Seguro ha ido paralela a los vacíos de protección social que los Estados han ido dejando. En este sentido, el crecimiento de los ramos de 
En su necesidad de incrementar la producción y aumentar las cuotas de mercado las compañías intensifican sus esfuerzos comerciales. A nivel interno, se insta al personal administrativo a desarrollar tareas de venta y atención al público, hasta el punto de que en algunas empresas se les denomina comerciales internos ${ }^{11}$. A nivel externo, se inicia un profundo proceso de reestructuración y cambios en las redes agenciales. Por un lado, la necesidad de incrementar los índices de producción lleva a las compañías a exigir a sus agentes una dedicación completa a la actividad: son "los nuevos profesionales". Por otro, en el proceso de aumento de beneficios, las compañías van a crear redes de venta específicas, esto es, equipos de vendedores/as que se dedican generalmente a la venta de productos de un solo ramo, aquel cuyo crecimiento interese potenciar. Estas redes aparecen fundamentalmente en el ramo Vida, ramo de especial atractivo para las entidades aseguradoras por sus altos beneficios y escasas pérdidas, y en él van a centrar gran parte de sus esfuerzos comerciales.

En general, la necesidad de reducir gastos (racionalizar la producción) lleva a intensificar el control sobre las redes agenciales ${ }^{12}$ y a aumentar sus funciones: se tiende a involucrar al agente no sólo en la producción (contratación del seguro) sino también en las funciones de gestión (atención al asegurado) de cada contrato de seguro, funciones estas que antes asumía el inspector, ya que el agente era un mero "avisador".

Todas estas transformaciones se integran en el discurso de la "profesionalidad". A diferencia de la situación "tradicional", ya no se quiere un agente a tiempo parcial y sin formación: ahora se quiere "un profesional". En realidad, lo que esto indica es una tendencia a seleccionar personas más productivas. Se trata, en definitiva, de racionalizar las redes de venta. La siguiente cita de un director comercial resume el significado del "agente profesional":"un negocio rentable es un negocio que tiene unos costes fijos, porque a costes fijos puedes calcular un crecimiento, un plan de acción, puedes hacer un programa a medio

Vida y Salud se encuentra en relación directa a las actuales políticas gubernamentales que anuncian dificultades a la hora de garantizar unas prestaciones públicas adecuadas en materia de pensiones y sanidad.

Por la misma razón, el ramo de decesos (el vocablo decesos es utilizado por las compañías aseguradoras para evitar el uso de la palabra muerte: decedere, marchar, decessus, el que se ha ido), el popular "seguro de los muertos", fuertemente arraigado en Andalucía, es el que ha mantenido una evolución más regular y estable desde sus orígenes hasta el momento actual: no casualmente los gastos de sepelio, ineludibles en nuestra sociedad, no han sido nunca cubiertos por el Estado.

11 Estas transformaciones constituyen una de las actuales preocupaciones sindicales del sector: la reclasificación de las categorías profesionales.

12 El control estadístico de la red agencial que posibilita la informatización permite realizar un seguimiento diario de la producción y gestión de cada agencia, controlando los índices de crecimiento, de siniestralidad... 
plazo, un programa a largo plazo, ese es el agente profesional. El agente profesional no es más ni menos que un programa establecido con unos costes fijos que requiere una inversión al principio pero que luego con el tiempo se te va reduciendo al.coste ideal que tú quieres tener".

Aparece una nueva terminología en torno a la profesión: asesores en vez de agentes (ya no se trata de vender sino de asesorar), jefes de equipo, supervisores, comerciales externos, comerciales de organización, ejecutivos comerciales, directores de agencia en vez de inspectores..., terminología que trata de enfatizar el caráctêr de servicio que, desde la nueva cultura empresarial, necesita la profesión. En unos momentos de gran competencia y homogeneidad en la oferta, el servicio al cliente va a ser el factor que las compañías abanderan para su diferenciación. A través del énfasis en el servicio al cliente, la empresa justifica la transferencia de las funciones de gestión de cada contrato de seguro a manos del agente, planteándolo como una parte consustancial al trabajo del verdadero profesional de seguros.

Por otro lado, las compañías desarrollan nuevas prácticas de integración/involucración de los y las agentes en la empresa, cuyo contenido es más simbólico que material: revistas de información interna sobre la marcha, objetivos y eventos acaecidos en la compañía, oferta de cursos de formación interna, reuniones para conocer e intercambiar opiniones.

Estos discursos y prácticas empresariales buscan legitimar las nuevas formas de gestión de la fuerza de trabajo que implican un aumento del control. En este marco, y como consecuencia de las estrategias empresariales puestas en marcha en el sector, las mujeres se incorporan a la venta de seguros.

\section{Las agentes de seguros, seres sexuados}

Dentro de un proceso más amplio de incorporación de las mujeres a nuevos ámbitos laborales, éstas acuden a una oferta de trabajo realizada en términos de profesionalización asexuada y se integran en los planes de carrera diseñados para "los nuevos profesionales". Sin embargo, si bien las tasas de rotación y abandono son muy elevadas para todos y todas, las mujeres se consolidan y permanecen en la profesión en menor proporción que los hombres.

La labor comercial requiere mucha "calle", un alto grado de interacción informal, y las mujeres en "la calle" se encuentran con grandes dificultades. Un agente joven, miembro de un equipo de "nuevos profesionales", narraba los comentarios de reprobación y alarma que recibía a causa del trabajo de su novia, agente de seguros en otra compañia. Un 
caso extremo de esta situación es el de una inspectora de una mutualidad de seguros, una de las pocas mujeres inspectoras en el sector, residente en un pueblo de la provincia de Sevilla, que se vio obligada a separarse de su marido a raíz de acceder a su puesto de trabajo: "Porque, por supuesto, no podía alternar el trabajo con la vida matrimonial: lo que pasa con las cosas de los pueblos, y de la gente, y de... Mi marido pensaba que me estaba acostando con todo el que me encontraba". Las mujeres son objeto de apropiación (Tabet, 1.989) por parte de un sólo hombre y cuando entran en circuitos de relación con otros hombres son susceptibles de apropiación general, al menos simbólicamente, por parte de todos los hombres con los que se relacionan.

La relación entre hombres y mujeres se plantea como una relación sexuada y en ese sentido las agentes de seguros encuentran grandes dificultades para desarrollar su trabajo. Los y las agentes, hombres y mujeres, venden seguros cómo y donde pueden, a pesar de las directrices empresariales sobre la forma ideal de realizar una venta. Sin embargo, mientras que un agente es visto como tal, la presencia de las agentes en la venta se sexúa: se las construye como mujeres antes que como profesionales y, por tanto, su interacción laboral es leída desde la lógica del sistema sexo-género. Un inspector que ha trabajado siempre en la provincia, en un mundo de hombres, cuenta cómo una agente de seguros de su red asumió la cartera de su marido porque éste tuvo problemas de índole personal. Desde que esto ocurrió, "la carteral3 ha venido a menos": "ganar la operación haciendo tiempo, tomando copas, no podía ser. El cliente se sentía raro, el marido también, ella también".

"La calle, las relaciones... Aquí se hacen muchos seguros en la calle, y los tíos siempre están por medio porque son los que deciden. Existe una aureola de sexo alrededor que en el hombre no se da, aunque eso se tiene que quitar con el tiempo". La presencia de las mujeres en la venta de seguros se sexúa, y esa sexuación, como dice nuestro informante, "en el hombre no se da". Los hombres son los sujetos sociales: las mujeres son percibidas, en cualquier contexto, como seres básica y primordialmente sexuados ${ }^{14}$.

Los contenidos de la construcción de género dominante han cambiado. El modelo ideal generado desde las clases medias que construía a las mujeres como amas de casa se ha

${ }^{13}$ Cartera: conjunto de pólizas de seguro conseguidas por un o una agente.

${ }^{14}$ En este sentido, A. Pesce, en una investigación llevada a cabo en la Weber, fábrica mecánica situada en Bolonia, Italia, lugar de trabajo históricamente ocupado por hombres, en el que ingresan un grupo importante de mujeres, constata cómo "La identidad obrera se ha construido y legitimado teniendo como punto de referencia a un sujeto concreto: el obrero adulto varón (...). Los únicos sujetos sexuados, en la Weber, son las mujeres; los hombres, por el contrario, son obreros; pero en cuanto que objeto sexuado a la mujer no se la reconoce una identidad laboral propia" (PESCE, A. (1.988), p.39). 
transformado y, aunque actualmente se predique su incorporación al ámbito "público" y, en concreto, al ámbito laboral, su presencia en estos espacios se sigue sexuando. "Cuando tú estás delante de un tío, sabes que no está pensando en acostarse contigo, porque eres un tío: está pensando en el trabajo. El cliente hombre, en el $40 \%$ de sus pensamientos, está pensando en cómo ligar contigo. Este es un añadido de problemas que no tenemos los hombres, y por eso ellas se queman más rápido". Salvo en los espacios en los que, como veremos, se las incorpora de forma explícita, la presencia de las mujeres como agentes de seguros es un fenómeno todavía incipiente porque la sexuación de las relaciones laborales dificulta su plena integración en este campo.

\section{La ductilidad del discurso sobre la profesionalidad}

Vista la situación, ¿qué ocurre con el discurso neutro sobre la profesionalidad?

El discurso formalmente neutro sobre el profesional de seguros se sexúa al interior para "explicar" la presencia de las mujeres en el sector: su "éxito" se plantea como un hecho que es necesario justificar.

El "éxito" de las mujeres se explica siempre en términos sexuados y generizados, no en términos de cualificación o aptitudes profesionales, y supone una consideración implícita de que los clientes son hombres.

La explicación más recurrente se puede resumir en la frase: "a una mujer se le abre la puerta con más facilidad que a un hombre". La incorporación de las mujeres a la venta de seguros se justifica planteando la existencia de una serie de ventajas en términos de género, la primera de las cuales sería el que no son percibidas socialmente como sujetos agresores ni como potenciales amenazadoras, por lo que la actitud del posible cliente será más relajada y menos hostil. También se incluyen, entre las cualidades de género femenino, la delicadeza, la bondad y la atención desinteresada por los/as otros/as, lo que las hace aparecer como más funcionales para la venta al público: tienen "las puertas abiertas".

Como se sigue pensando en los hombres como los únicos sujetos sociales activos, se plantea que es también "más fácil" que una mujer venda a un hombre. Las pautas de relación que deben presidir las relaciones sociales entre hombres y mujeres implican cortesía, amabilidad y deferencia hacia las mujeres, conceptuadas como seres débiles y delicados. Por tanto, se deduce que cualquier mujer va a tener más posibilidades de concertar una entrevista de venta que si lo intenta un hombre, y que el hombre-potencial cliente va a ir hacia ella con una actitud menos distanciada de la que adoptaría ante otro hombre. Desde esta lógica heterosexual (hombres y mujeres como seres complementarios) y desde la construc- 
ción social de la sexualidad masculina ${ }^{15}$, se plantea que siempre es más agradable la llamada o visita de una mujer: se la va a recibir con más facilidad. Un inspector al frente de equipos de nuevos profesionales, de 26 años, opina: "Si yo fuera cliente, a mí me es más agradable que venga una señorita (...) Es normal, es cuestión de naturaleza (...) Hay veces que la reciben aunque solamente sea por verla, pero, bueno, ya le están abriendo la puerta (...), lo tienen más fácil que nosotros". Es la lógica de la identidad sexual que establece, en palabras de Mathieu (Mathieu, 1.991, p.232) "el modelo de la heterosexualidad concebida en Occidente como la expresión de la Naturaleza". Por eso, en este sector se plantea la relación del cliente hacia la agente en términos de una atracción sexual de los machos hacia las hembras, atracción, en tanto que natural, instintiva y, en definitiva, "inevitable".

El discurso se generiza también para explicar el fenómeno de la inclusión de las mujeres en el ramo de Vida. Es importante señalar que en algunas compañías las redes de venta específicas en el ramo de Vida están compuestas exclusivamente por mujeres. Este hecho forma parte de una estrategia empresarial puesta en marcha para introducir un producto nuevo en el mercado. Vida es un producto de oferta, esto es, un producto que requiere una acción comercial mayor que otros, como, por ejemplo, los seguros de automóviles, que son obligatorios, o los de hogar, comercio o industria, en los que la iniciativa de compra suele partir de los y las clientes. Es un ramo todavía poco introducido, con grandes perspectivas de futuro y muy rentable. El interés de las entidades aseguradoras por campos de mercado en los que no tienen experiencia previa, les lleva a buscar agentes en colectivos con diferentes características a las requeridas hasta el momento. $Y$ es en este marco en el que se piensa en las mujeres ${ }^{16}$.

Lo importante de este hecho es que pone de manifiesto cómo el sexo funciona como criterio de formación de equipos de venta (las compañías de decesos, por ejemplo, han trabajado tradicionalmente con equipos de hombres), poniéndonos de manifiesto la funcionalidad de las relaciones sociales de sexo para la producción.

${ }^{15}$ Desde el S.XIX el pensamiento occidental construye una sexualidad masculina y una sexualidad femenina como dos entidades esencialmente diferentes. La sexualidad masculina se define como una sexualidad activa y fuertemente acentuada.

${ }^{16}$ No es desdeñable el hecho de las especiales características retributivas que rigen este ramo. La mayoría de los y las agentes se vinculan a la empresa por un contrato mercantil y su forma de retribución es la comisión, esto es, un determinado porcentaje sobre el importe de cada prima contratada. Además, reciben también una parte proporcional de esa comisión de las pólizas que siguen en vigor (derecho a cartera).

Los ramos del Seguro que necesitan pocas gestiones posteriores a la formalización de la póliza, como Vida y Decesos, apenas tienen comisiones de cartera. Las mujeres en la venta de seguros se encuentran fundamentalmente en aquellos ramos sin derecho a cartera. 
Para justificar esta división sexual del trabajo, esto es, la inserción de las mujeres en el ramo de Vida, se ha elaborado un planteamiento en unos términos que se podrían resumir en la frase "Vida es amor".

Los ramos del seguro se generizan y, en base a esta generización, se incluye o excluye a las mujeres."Si yo vengo a decirle a usted que vengo a hacerle una valoración de riesgos, se la puedo hacer como el mejor. Pero seguramente usted se va a fiar más del técnico de la compañia por el hecho de ser varón. Sin embargo, si vengo a ofrecerle un seguro de vida que cubra sus necesidades, usted a mí me va a contar cosas que a un hombre no le va a contar jamás". Esta comercial del ramo Vida sabe que no se trata de una cuestión de cualificación sino de generización de lo personal: ella se sabe capaz de realizar una valoración de riesgos pero su adscripción de sexo/género no la habilita para hacerlo, y sí, en cambio, para escuchar las confidencias del posible cliente. Se tiene conciencia de la imposición de comportamientos sociales en base al sexo biológico (Mathieu, 1.991, p.239), imposición ante la que se han constatado reacciones diversas. En ocasiones, cuando las comerciales han estado en situación de rechazar posibles operaciones, no han tolerado esa infravaloración profesional. Otras veces, desde la conciencia clara de la situación, "aprenden" a convivir con ella: "En cuanto a dudar de tu capacidad profesional, (...) eso al principio te produce mucho nerviosismo (...), hasta que aprendes". La variedad de respuestas encontrada no pone de manifiesto el carácter vivo, dinámico y en continuo proceso de transformación de las relaciones sociales.

Todas las cualidades que se atribuyen a las mujeres se sitúan en el polo de las emociones: intuición, sicología, capacidad de escucha, menor agresividad, trato más agradable... En base a la construcción dicotómica de los géneros, esto significa la exclusión automátiça de los contextos y actividades que precisan de cualidades que se sitúen en el polo de la racionalidad.

Los discursos que explican su incorporación, por formar parte de una clasificación dicotómica y jerarquizada (Delphy, 1.991), funcionan como discursos de dominación que dificultan que las prácticas laborales sean motores de transformación. El discurso asexuado sobre la profesión de agente de seguros no va realmente referido a los dos sexos; en su planteamiento androcéntrico va implícita la consideración de que los hombres son los únicos "hombres"17.

${ }^{17}$ Utilizando una frase de Collier y Yanagisako, "Los/as antropólogos/as feministas, a través de la práctica de luchar contra la desigualdad sexual, han llegado a reconocer que aquellos que utilizan la palabra hombre demasiadas veces se refieren precisamente a eso" (Collier, J.F. y Yanagisako, S., 1.989, p.37). 
El discurso sexuado empresarial no atiende en las mujeres, como sí lo hace en los hombres, en primer lugar a su formación y cualidades comerciales, sino al hecho de ser mujeres, de "tener sexo"; de no ser así, éstas sería igualadas a quienes son considerados como los verdaderos profesionales de seguros: los hombres. Su incorporación a la venta como "mujeres", no como profesionales, las devuelve al lugar subordinado que ocupan en las relaciones sociales de sexo.

Hemos visto cómo se reactualiza la ideología sobre los sexos dominante en un sector "moderno", supuestamente asexuado, y cómo la venta de seguros no sólo se apoya en las relaciones sociales de sexo, presuponiéndolas, sino que las refuerza, porque ello resulta funcional para el despliegue productivo del sector. Analicemos ahora cómo esas mismas relaciones condicionan también las prácticas profesionales, los discursos y las representaciones de los y las sujetos sociales implicados.

\section{Las p̀ácticas de profesionalización: mujeres y hombres en la venta de seguros}

La venta de seguros lleva implícita una interacción directa entre individuos en la cual la imagen, la "buena presencia", aparece como un requisito primordial.

En el caso de los agentes, ir arreglado, bien presentado, significa, sin lugar a dudas, chaqueta y corbata; ponerse "el uniforme", utilizando una frase repetida en el sector. Para las agentes, en cambio, no hay "uniforme" definido, salvando el traje de chaqueta, versión femenina del "uniforme" masculino.

Si consideramos la moda como una forma de intervención sobre el cuerpo, destinada a actualizar y poner en escena el sexo (Gúillaumin, 1.992), la existencia de mayores posibilidades en el atuendo de las agentes debería ser interpretada como una sexuación más elaborada de su cuerpo. Por ello, su adecuación a la norma, a la estética dominante, va a conllevar mayores exigencias (Mendez, 1.995). "Siempre tengo que salir a la calle muy pintada, muy arreglada, muy entaconada y muy contenta. $Y$ eso es muy duro", confesaba una comercial. Como se refleja en esta cita, las agentes acusan esas exigencias, mientras que los agentes se quejan de que "ellas lo tienen más fácil", ya que desde su experiencia la diferencia no es vivida como una imposición social.

Si no hay "uniforme", sí existe en cambio una norma bastante consensuada: no ir "llamativa", no ir "demasiado atractiva", no muy "despampanante", no ir "excesiva". Vimos como a las agentes se las define primordialmente como seres sexuados y, en este sentido, si una de las funciones sociales del cuerpo es actualizar, visibilizar, lo que se considera como 
la principal división de la especie humana, el sexo (Guillaumin, 1.992), velarla o, al menos, no acentuarla, se va a presentar como el primer requisito para establecer una relación profesional con los clientes hombres, constituyéndose en una de las preocupaciones de las agentes en sus prácticas laborales. El cuerpo de estas, desde la lógica de la identidad sexual predominante en el sector, va a convertirse en un obstáculo para la profesionalización. “ $A$ lo mejor, en casa, me siento y se me ve la rodilla, pero en las entrevistas yo me siento con cuidado de que no se me vea la rodilla, para que nadie llegue a pensar que esta persona viene...Estoy allí como profesional, como lo que soy", explica una comercial. Utilizar el cuerpo para la venta, frente a cierta lógica social, es un elemento de desprestigio profesional, ya que inscribe a las agentes en unas relaciones estructurales de desigualdad.

Cuando un o una agente se plantea vender seguros, el método para obtener clientes más usado, y a la vez el más recomendado por las compañías, es la utilización y profundización de las redes sociales. En sus manuales y cursos de formación sobre técnicas de venta, las empresas recomiendan empezar por las personas conocidas, directa o indirectamente, y seguir obteniendo nuevos nombres de las visitas realizadas. El recurso a las relaciones de amistad, parentesco u otras debe ser combinado con el recurso a otros espacios en los cuales no se posee un contacto previo. Dada la heterogeneidad social del sector ${ }^{18}$, la gama resultante es muy amplia y variada y, en ese sentido, hemos comprobado que no se produce una diferenciación en el uso de espacios categorizados socialmente como "domésticos" por las mujeres y espacios "públicos" por los hombres. Este hecho deconstruye las dos trilogías características de la ideología capitalista "producción"-ámbito "público"-espacio "masculino" versus "reproducción"-ámbito "privado" o "doméstico"-espacio "femenino", en dos sentidos: primero, poniendo de manifiesto cómo el sector utiliza los distintos ámbitos de la vida social para su despliegue productivo y segundo, poniendo de manifiesto cómo ambos sexos lo hacen para su despliegue profesional. En la labor de venta, los y las agentes recurren a una misma utilización de marcos de relación social y a la búsqueda de elementos de afinidad con sus clientes.

La fuerte personalización de las relaciones sociales es una característica importante de la etnicidad andaluza (Moreno, [1.981] 1.993) que acentúa aquí los contenidos "humanos" de la interacción social en la venta de seguros. Como señala un inspector: "hay otras zonas en que se nota que están más deshumanizadas. Yo hablo con compañeros de Madrid o Barcelona de aspectos que llevo con corredores o agentes de aqui y ellos se ponen las manos en la cabeza: ¡cómo es posible que lleguéis a esos extremos!. Extremos que puede ser entrar en una agencia como si entraras en tu casa. No, alli hay que entrar con una cita

${ }^{18}$ Un estudio realizado en 1.993 entre los agentes que componen el mercado asegurador con más de un año de antigüedad en la profesión concluye que esta no es propia de ningún colectivo especial de población (Fuente: (1.993) Encuesta a agentes afectos. Estudio de opinión comparativo, ICEA). 
previa y no sé qué... Aquí, quizá sea también por la propia idiosincrasia del país en el que estamos".

Sin embargo, entre los elementos que adquieren mayor relevancia destacan los que tienen que ver con los marcos de relación social en términos de sexo-género: "Cuando está casada [la cliente], tengo tantos hijos, ;ah!, pues yo tengo estos, me intento identificar un poco con ella, no hacerle la pelota pero sí intentar ir a su terreno para llevarla al mío". En la búsqueda de afinidades, esta comercial habla de identificarse con sus clientes mujeres en cuanto madres. Aunque en estos momentos ella se sitúe como profesional y no como madre, en su discurso utiliza la maternidad como un elemento identificatorio en aras a la consecución de su objetivo.

Existen temas comunes utilizados por ambos sexos. Por ejemplo, conversar e interesarse por la familia. Otros son más específicos. Entre hombres, presentan una mayor recurrencia los deportes, en concreto el fútbol. Un inspector, sevillista, analiza los posibles inconvenientes de no manejar adecuadamente este elemento identificatorio: "el fútbol es muy importante también (...) El que yo sepa que es del Betis hace que yo no hable de fútbol nunca, porque se puede ofender". Otros elementos son los coches, o las mujeres: "es muy presumido. (Decirle) D. Antonio, cómo le mira esa mujer, o cualquier tontería de esas".

Existen contextos en los que estos elementos aparecen ligados a elementos étnicos, fundamentalmente en las formas de sociabilidad andaluza en las que destacan los contextos de interacción informal que se establecen entre hombres ${ }^{19}$. Un inspector cuenta cómo en su trabajo es importante adaptarse a las pautas de relación de los clientes, fumar, beber: "creo que en el norte, lo sé por los compañeros, es de otro estilo, pero aqui se hacen muchos tipos de negocios y tratos en la calle".

En sus representaciones sobre los y las clientes, los y las comerciales reproducen los estereotipos de género vigentes. Cuando se refieren a seguros que afectan al ámbito familiar (seguros personales, seguros de hogar), ambos parten de la base de que, con independencia de la persona que suscriba la póliza, son los hombres los que toman la decisión de contratar un seguro. Desde este punto de vista, las veces que ellas son contempladas como sujetos activos en el proceso de toma de decisiones lo son como obstáculos en el camino hacia el verdadero sujeto de decisión: "estropean muchas operaciones" porque no ven la necesidad (atribución de una menor "conciencia aseguradora"), o porque se preocupan por el gasto (alusión al papel de administradora de la economía doméstica) o, en último térmi-

${ }^{19}$ Ya señalamos la notable ausencia de estudios sobre la sociabilidad de las mujeres, en Andalucía. Existen un importante número de estudios sobre cofradías, peñas... de hombres, que a pesar de que son estudios de sexogénero, no se conceptúan como tales, porque siguen considerando a los hombres como los únicos sujetos socia- 
no, porque, aunque no lo parezca, son ellas las que "llevan la batuta en casa" (se acude al estereotipo sobre el supuesto poder oculto de las mujeres).

Si cuando venden aplican comportamientos estereotipados a sus clientes, no ocurre lo mismo en lo referente a sus preferencias de venta, que, a pesar de la ideología sobre los sexos vigente que generiza los ramos del Seguro, no están condicionadas por su adscripción de sexo-género sino por su inserción en un proceso productivo concreto. Los y las agentes, o bien no manifiestan preferencias por uno u otro ramo, dentro del discurso general sobre la actividad aseguradora que plantea que cualquier necesidad es igualmente importante, $o$ si lo hacen es motivados por razones de tipo económico (aquellos seguros que dejen más comisión).

En la gran mayoría de los casos, no hay una relación estructural de dependencia de carácter total entre comerciales y empresas. Por un lado, la demanda de agentes es continua en todas las compañías aseguradoras. Por otro, la vía de reclutamiento de la fuerza de trabajo que se prefiere en el sector es la captación directa o personalizada; dentro de ella, una práctica muy frecuente es acudir a "la competencia", esto es, a los y las profesionales ya existentes en el sector. Ambos factores provocan que el grado de supeditación respecto a una entidad concreta sea débil.

En este contexto, las vías más usuales de consolidación y/o promoción en el sector son los continuos cambios de compañía. A pesar de los estereotipos de género existentes en el sector ("las mujeres son más estables y fieles a su compañía, se comprometen más, son más constantes"), la posibilidad de traslado forma parte de la cultura del trabajo de ambos sexos. Salvo excepciones, quienes participan en la venta de seguros tienen interiorizada la movilidad en un sector que está viviendo importantes reestructuraciones como consecuencia de las fusiones y absorciones entre compañías, donde los cambios en la política comercial de cada empresa son frecuentes y en el que la experiencia comercial es uno de los principales criterios de contratación.

Acorde con sus prácticas de profesionalización, para los y las comerciales lo principal es el propio sujeto comercial; a pesar de la existencia de una acentuada cultura empresarial que transmite la idea de la importancia de pertenecer a una compañía solvente por estar fuertemente consolidada en el mercado, pertenecer a un grupo multinacional con visión de futuro o cualesquiera otras características, los y las comerciales, desde sus culturas del trabajo, relativizan el grado de importancia de estos factores. Por un lado, y como las estadísticas corroboran, los clientes (hombres y mujeres) contratan sus seguros motivados más por la persona concreta que se los venda que por la compañía para la que esta persona trabaje. Por otro, como acabamos de señalar, la dinámica de funcionamiento del sector permite unos márgenes de acción al individuo que no existen en otros sectores. 
En los primeros momentos, sobre todo si se llega sin un conocimiento previo del sector y sin ningún tipo de formación en la venta de seguros, es fácil que se interiorice la cultura empresarial: la empresa, a través de sus prácticas de integración-involucración-motivación, consigue sus objetivos. Sin embargo, pasados los momentos iniciales, el ejercicio de la profesión, el conocimiento del sector y el pragmatismo en las actuaciones empresariales activan la importancia que los y las agentes se conceden a sí mismos sobre la importancia concedida a la compañía, convirtiéndose esta valoración en un elemento importante de sus culturas del trabajo.

En esta línea, frente al papel que la empresa concede a la formación, a la idea de que el comercial "se hace" (es decir, lo "hace" la compañía), los y las comerciales ya incorporados a la profesión defienden que el comercial "nace", poniendo ejemplos de una infancia en la que ya afloran dichas dotes y, si poseen antecedentes comerciales en la familia, pueden llegar a plantear que han heredado de ellos su "vena comercial".

\section{Los tiempos de trabajo}

La venta de seguros no está sujeta a horarios; cada persona puede intentar realizar sus ventas cuando más convenga a sus intereses, adaptarse a los horarios de la clientela o intentar combinar ambas cosas. Puesto que se trabaja por objetivos de producción, cumpliendo los mínimos que fijan las compañías es posible marcarse unas metas o ingresos en función de los cuales dedicar más o menos horas a la venta. Estas condiciones permiten un amplio abanico de situaciones, desde personas que ejercen a tiempo completo a dedicaciones a tiempo parcial (amas de casa, gestores/as, abogados/as, personal al frente de talleres mecánicos...).

Una condición importante para el éxito en la venta de seguros es aprovechar las circunstancias cotidianas para ampliar constantemente el mercado de clientes. Cualquier situación y cualquier persona es asegurable: un o una agente es agente de seguros esté donde esté. Prestar atención a las circunstancias cotidianas aprovechando cualquier oportunidad que esta brinde, dedicar tiempo a pensar cómo resolver situaciones y solucionar gestiones desde el domicilio si es necesario. Digamos que ser agente de seguros proporciona una peculiar visión de la realidad social. Es muy significativo el siguiente texto extraído de un manual de técnicas de venta: "Cuando decimos “ ¿Cómo está usted" estamos preguntando ¿Cómo está su estado de salud?. Si preguntamos “ ¿Cómo va el trabajo?” estamos intentando averiguar cómo está la situación económica. Si preguntamos “ ¿Cómo están sus hijos?" posiblemente podamos enterarnos de sus preocupaciones de futuro" 20 .

${ }^{20}$ Fuente: Curso básico de Seguros. Cuarta parte: Técnicas elementales de venta. Material formativo de Catalana Occidente. p. 125. 
Desde el momento en que el ámbito laboral se superpone a otros ámbitos de la vida social y, en concreto, al familiar, surgen conflictos. El rol de las agentes en la división sexual del trabajo en el ámbito doméstico entra en contradicción con su rol como profesional, por lo que este se somete a un proceso de negociación familiar, que con frecuencia supone la imposición de "desenchufar" al incorporarse al trabajo doméstico y a las relaciones familiares, lo cual implica una restricción a esa "disponibilidad total" que caracteriza el trabajo comercial. A veces aparecen conflictos familiares ${ }^{21}$ y las respuestas a estas situaciones son variadas, desde emplear servicio doméstico hasta renunciar a mayores niveles de dedicación a la profesión. Para muchas mujeres, el salario supone un medio de contratar la realización de tareas que antes asumían directamente (tareas domésticas y cuidado de hijos), quedando en sus manos tan sólo la labor de supervisión. La atención directa al marido es una tarea difícilmente contratable desde los parámetros culturales de nuestra sociedad.

Frente al discurso hegemónico que sitúa a las mujeres "más cómodamente" en los trabajos administrativos, los aspectos que ambos sexos valoran más de la profesión son la mejora económica y de estatus, la experiencia, el bagaje que proporciona el contacto con un amplio espectro de personas de muy distintas características y en muy distintas situaciones, y las posibilidades de "desarrollo personal", de "crecimiento", muy enfatizadas estas últimas por el discurso empresarial.

Junto a los anteriores, se concede mucha importancia a la "flexibilidad" de horarios: cada cual organiza su tiempo y su trabajo, es dueño/a de su horario, decide cuando entra y sale de la oficina; en definitiva, ser el propio jefe, como expresa una frase utilizada de forma recurrente. Los y las comerciales se declaran incapaces de someterse a un horario fijo. "La calle" es su pasión. Sin salir a vender -afirman con frecuencia- se asfixian. Les cambia el humor. Necesitan actividad, movilidad, dinamismo. Por ello, una de las tareas menos valoradas del trabajo son las gestiones burocrático-administrativas (los colectivos sociales se definen en oposición a "los otros" y, en este caso, ese "los otros" lo constituye el personal administrativo del sector).

El alto grado de dedicación que, dadas sus características retributivas, exige la profesión para conseguir unos ingresos suficientes, lleva a los y las comerciales a exaltar la libertad de horarios, o la de organización, como un mecanismo de compensación simbólica de las duras condiciones de trabajo.

${ }^{21}$ Las compañías, cuando "venden" la profesión de agente de seguros, explicitan como uno de los requisitos necesarios para triunfar el apoyo familiar, es decir, el conjunto de personas que hacen posible que el individuo desarrolle su capacidad productiva para la empresa y le ofrezca ese grado de dedicación que estas exigen a sus "nuevos profesionales". El apoyo familiar se plantea en principio en términos de apoyo moral, de aliento y de aprobación. 
Si ambos, hombres y mujeres, valoran la "flexibilidad" como una característica plenamente satisfactoria de la profesión, ello tiene consecuencias muy distintas en lo referente a la vida familiar. Las mujeres casadas plantean que es una ventaja porque permite compatibilizar su empleo con el trabajo doméstico y con los imprevistos en el ámbito familiar, como enfermedades u otras circunstancias. Los hombres casados, en cambio, plantean que la "flexibilidad" tiene algunos inconvenientes, sobre todo en cuanto a que no les permite dedicar tiempo a la vida familiar. El diferente significado de un mismo hecho para personas que ocupan los mismos puestos de responsabilidad laboral pone claramente de manifiesto la obligatoriedad de la asunción del trabajo doméstico por las mujeres y el carácter de descanso y gratificación que tiene para los hombres este mismo ámbito.

Para "triunfar" en la profesión hay que contar con una disponibilidad de tiempo que en el caso de las agentes entra en contradicción con los roles de sexo socialmente asignados. Por ello, cuando una mujer "triunfa", la ideología sobre los sexos dominante elabora nuevas respuestas que reactualizan la lectura subordinada de su situación: la mujer funciona bien cuando toma el trabajo como algo a tiempo parcial; si no, ya se sabe que una mujer en el terreno comercial, "o es soltera o divorciada o algo asî", en palabras de un director comercial.

Como vemos, las culturas del trabajo de los y las agentes de seguros aparecen condicionadas no sólo por su inserción en un proceso productivo concreto que genera una cultura empresarial específica, sino por su inserción en unas relaciones sociales de sexo y en una etnicidad determinada. La articulación de estos tres factores explica que los discursos, las representaciones y las prácticas resultantes sean en ocasiones contradictorias y estén en continua reelaboración, a veces asumiendo, a veces impugnando, las ideologías dominantes, en un proceso dinámico de interacción social.

\section{BIBLIOGRAFÍA}

COLLIER, J.F. Y YANAGISAKO, S. (1.989) "THEORY IN ANTHROPOLOGY SINCE FEMINIST PRACTICE", EN CRITIQUE OF ANTHROPOLOGY, VOL. 9,(2), PP. 27-37.

DELPHY, C. (1.991)'PENSER LE GENRE: QUELS PROBLÈMES?", EN SEXE ET GENRE. DE LA HIÉRARCHIE ENTRE LE SEXES, PARIS, CNRS.

EDWARDS, R. (1.983) “CONFLICTO Y CONTROL EN EL LUGAR DE TRABAJO”, EN TOHARIA, L. (COMP) EL MERCADO DE TRABAJO. TEORÍA Y APLICACIONES, MADRID, AlIANZA EDITORIAL. PP 141-155.

FINN GARNER, JAMES (1.994) CUENTOS INFANTILES PolítiCAMENTE CORRECTOS, BARCELONA, CIRCE EDICIONES. 149 PP. 
GUILlaUmin, C. (1.992) "Le CORPS CONSTRUTT", en SEXE, RaCE et PRACTIQUe de PoUVOIR, PARIS, ED. CÔTÉ-FEMAMES. PP 117-143.

KERGOAT, D. [1.984] "PoR UNA SOCIOlOGÍA DE LAS RELACIONES SOCIALES. DEL ANÁLISIS CRÍTICO DE LAS CATEGORÍAS DOMINANTES A UNA NUEVA CONCEPTUALIZACIÓN", BORDERIAS, C., CARRASCO, C. Y ALEMANY, C. (1.994) LAS MUJERES Y EL TRABAJO. RUPTURAS CONCEPTUALES,BARCELONA, ICARIA-FUHEM. PP 515-531.

MATHIEU, N.C. (1.991) "IDENTITÉ SEXUELlE/SEXUÉE, DE SEXE? TROIS MODES DE CONCEPTUALISATION DU RAPPORT ENTRE SEXE ET GENRE", L'ANTOMIE POLITIQUE. CATEGORISATIONS ET IDÉLOGIES DU SEXE, PARIS, CÔTÉ-FEMMES ÉDITIONS. PP 227-266.

MENDEZ, L. (1.995) "RECETARIOS MÁGICO-CIENTÍFICOS AL SERVICIO DE LA ESTÉTICA DE LA DELGADEZ: CUERPOS DE MUJERES, CUERPOS DE HOMBRES", ANOREXIA. DIETA, ESTÉTICA Y Crenzas, Santiago de Compostela, Museo do Pobo Galego. pP 117-127.

MORENO, I. (1.993) ANDALUCÍA: IDENTIDAD Y CULTURA (ESTUDIOS DE ANTROPOLOGÍA ANDAluZa), Málaga, Ed. Librería Agora. 150 PP.

NAROTZKY, S. (1.988) TRABAJAR EN FAMILIA. MUJERES, hOGARES Y TALLERES, VALENCIA, EDICIONS ALFONS EL MAGNANIM. 183 PP.

PESCE, A. (1.988) "LOS CONFLICTOS DE SEXO EN EL TRABAJO: REFLEXIONES A PARTIR DE UNA INVESTIGACIÓN EMPÍRICA EN ITALIA" SOCIOlogía del TRABAJO № 3, MADRID, ED. SXXI. PP 35-61.

TABET, P. (1.989) "DU DON AU TARIF. LES RELATIONS SEXUELLES IMPLIQUANT UNE COMPENSATION", LES TEMPES MODERNES, № 490. PP 1-53.

VERDIER, E. (1.980) “INFORMATISATION ET ÉVOLUTION DE LA DIVISION DU TRAVAIL DANS LE SECTEUR DES ASSURANCES" CRITIQUES DE L'ECONOMIE POLITIQUE. NOUVELle SERIE №12 24F, JULLIET-SEPTEMBRE.

WEEKS, J. (1.993) EL MALESTAR DE LA SEXUALIDAD. SIGNIFICADOS, MITOS Y SEXUALIDADES MODERNAS, MADRID, TALASA ED. 426 PP. 